\title{
Study on the superiority of a high polymer (HDPE) self-adhered waterproofing membrane in construction
}

\author{
Yudian $\mathrm{Li}^{1, *}, \mathrm{Na} \mathrm{Li}^{2}$, Yanjun $\mathrm{Shi}^{1}$, and Zhijun $\mathrm{Jia}^{2}$ \\ ${ }^{1}$ Beijing Urban Construction Yatai Group Co., Ltd. Dongtucheng Rd.No.9, Beijing, 100013,China \\ ${ }^{2}$ Tangshan Yuandahongyu Waterproof Material Co., Ltd. Building 4-15, North jingluetianze Park, No.1, Tongtai Road, Taihu Town, \\ Tongzhou District, Beijing, 1011493,China.
}

\begin{abstract}
With the rapid development of urbanization in China, people's requirements for the quality of life and environment are constantly improving. However, the shortage of resources and the deterioration of environment are becoming more and more serious. Environmental protection has become the only way for the sustainable development of society. Therefore, the application of more and more new green building materials has become the key to the sustainable development of the construction industry. In the face of the rapid development of modern construction industry, engineering quality and functional requirements have become the basic requirements, the green environmental protection has become a higher requirement. The application of green environmental protection building materials in engineering construction is the main development direction of the transformation of modern construction industry. At the same time, it conforms to the policy of environmentally sustainable development of all sectors of society, and promotes the construction industry to meet the higher requirements of green environmental protection living environment. This paper studied the performance and waterproof mechanism of a kind of high polymer (HDPE) selfadhered waterproofing membrane and its application in construction. Compared with the traditional waterproofing membrane, the high polymer self-adhered waterproofing membrane can give full play to the advantages of environmental protection on the premise of meeting the building quality.
\end{abstract}

\section{Introduction}

Waterproof engineering is an indispensable part of the construction process. The building is in the external environment, affected by the external environment for a long time, infiltrated and eroded by rainwater and groundwater, which is very easy to reduce the use function of the building, and even seriously affect the safety of the structure. Therefore, the building must be isolated and protected by waterproof materials.

At present, there are many researches on new waterproof materials, mainly in the construction process. For example: K. Yang ${ }^{[1]}$ put forward the conclusion that it is necessary to accelerate the development and application of green building waterproof materials. D. Yang et al. ${ }^{[2]}$ introduced the construction technology of high polymer ( HDPE) self-adhered waterproofing membrane, and explained that the high polymer selfadhered waterproofing membrane is superior to the traditional waterproof roll in technical quality. K. Zhao et al. ${ }^{[3]}$ combined with the solid engineering, carried out the research on the lap joint for the construction of polymer self-adhered waterproofing membrane (pre lay and anti-stick method). Z. Li et al ${ }^{[4]}$ combined with the engineering examples, made in-depth study on the advantages and disadvantages of the longitudinal lap of the new green building materials (polymer self-adhered waterproofing membrane), as well as the ingenious prelaying construction technology. Through the application of green environmental protection materials in the field of civil engineering, $T$. Ouyang ${ }^{[5]}$ expounds that the application of green environmental protection building materials can not only achieve the goal of energy conservation and environmental protection, but also help to save construction costs, hoping to promote the application of green environmental protection materials in the field of civil engineering and other conclusions.

At present, there are many kinds of waterproof materials on the market, and the waterproof materials are constantly innovating. According to the construction experience in recent years, the author chooses the high polymer (HDPE-High density polyethylene) self-adhered waterproofing membrane and the traditional SBS modified asphalt waterproofing membrane for comparative analysis based on the premise of construction quality and the purpose of environmental protection. Combined with the test data of waterproof membrane, the superiority of high polymer (HDPE) selfadhered waterproofing membrane summarized and analyzed.

\section{Introduction of high polymer (HDPE) self-adhered waterproofing membrane}

* Corresponding author: liyudian_bucg@126.com 


\subsection{Waterproof mechanism}

AS shown in Fig.1 high polymer (HDPE) self-adhered waterproofing membrane is composed of high polymer (HDPE) sheet layer, high polymer hot melt pressuresensitive adhesive layer and inorganic particle (reaction sand) layer. During the waterproof construction, the high polymer (HDPE) self-adhered waterproofing membrane is pre-paved on the concrete cushion of the underground structure, the main HDPE sheet is facing the cushion, the surface high polymer hot melt pressure-sensitive adhesive layer and the supporting inorganic reaction sand layer are facing the post cast concrete structure, through bonding with the post cast concrete structure, a whole closed waterproof isolation system is formed, which plays the waterproof function. Compared with the traditional SBS modified asphalt waterproofing membrane, the waterproof performance is more stable.

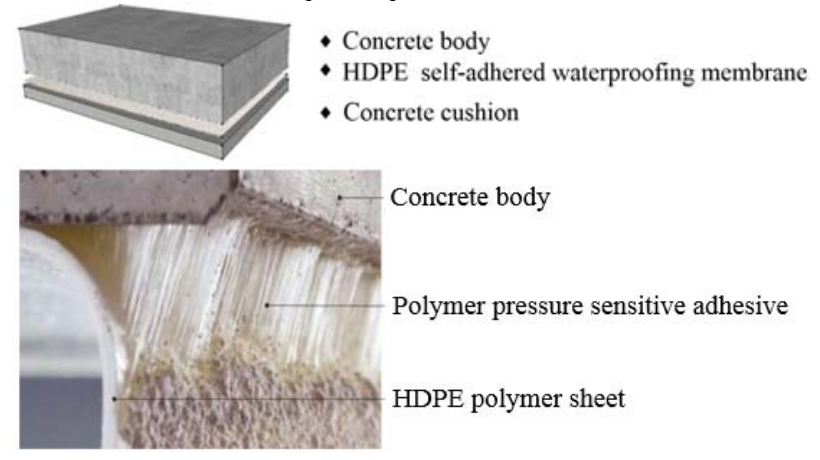

Fig. 1. HDPE self-adhered waterproofing membrane

\subsection{Superiority}

The first one is the waterproof mechanism: the strength of the concrete structure of the building is generally greater than the strength of the cushion. Because of the accumulation of the structural load in the later period, the base soil under the cushion undergoes slight settlement change. Or due to the effect of groundwater, the local slab bottom under the cushion will be hollowed out, which will easily lead to the broken or cracked cushion, so that the cracking of traditional SBS modified waterproofing membrane will affect the waterproof performance. High polymer (HDPE) self-adhered waterproofing membrane, which is self- adhered with the main structure, is used to attach to the main structure of the building. The main structure of the building has little deformation due to its high strength and rigidity, thus ensuring the waterproof performance.

The second one is the perspective of waterproof laying: high polymer (HDPE) adhered is laid by prelaying and sticking process. Compared with the traditional SBS modified asphalt waterproofing membrane by hot-melt process, it has less lap joints, which can effectively prevent the water leakage of the bonding surface. At the same time, the pre-laying and anti-sticking construction does not produce asphalt smoke, which is conducive to atmospheric environment protection.

\subsection{Scope of application}

High polymer (HDPE) self-adhered waterproofing membrane has a wide range of application due to its advantages of superior waterproof, outstanding durability, good mechanical properties, green environmental protection and unique construction methods. For example, the underground comprehensive pipe gallery, all kinds of building basements (bottom plate, external protection and internal side wall), tunnels, pipe gallery, culverts, water conservancy dams, municipal construction waterproof and anti-seepage works are applicable.

\section{Performance analysis of high polymer (HDPE) self-adhered waterproofing membrane}

\subsection{Environmental performance}

Environmental protection performance of building waterproof membrane products shall comply with the standard: Technical requirement for environmental labeling products-waterproof rolling materials ${ }^{[6]}$. The main raw materials of high polymer (HDPE) selfadhered waterproofing membrane include high density polyethylene, high polymer hot-melt pressure-sensitive adhesive, inorganic reactive sand, etc. The main raw materials of traditional SBS modified asphalt waterproofing membrane are styrene butadiene styrene (SBS) thermoplastic elastomer modified asphalt agent, polyethylene film, fine sand, mineral sheet (particle) or aluminum foil, copper foil and other isolation materials.

In terms of environmental protection index, high polymer (HDPE) self-adhered waterproofing membrane has significant advantages. Taking SBS II PY PE PE 4 elastomer modified asphalt waterproofing membrane as an example, in the detection of soluble $\mathrm{Cr} \mathrm{mg} / \mathrm{kg}$ index, the measured value of high polymer (HDPE) selfadhered waterproofing membrane is $50 \%$ of the measured value of modified asphalt membrane. The measured results of main environmental indicators are as shown in Table 1 and Table 2.

The high polymer (HDPE) self-adhered waterproofing membrane is outstanding in its own environmental protection performance. This kind of products in the field construction, the use of selfadhesive method or welding method, instead of the traditional hot melt method of hot work construction, avoid the production of hydrocarbon such as asphalt smoke, reduce air pollution and soil pollution. Therefore, compared with the traditional asphalt waterproofing membrane, the high polymer (HDPE) self-adhered waterproofing membrane has more outstanding environmental protection performance. 
Table 1. Test results of high polymer (HDPE) self-adhered waterproofing membrane

\begin{tabular}{|l|l|l|c|l|l|}
\hline No. & \multicolumn{1}{|c|}{ Test content } & Test Standard & $\begin{array}{c}\text { Standard } \\
\text { requirements }\end{array}$ & \multicolumn{1}{|c|}{ Test results } & \multicolumn{1}{|c|}{ Judgment result } \\
\hline 1 & soluble $\mathrm{Pb}, \mathrm{mg} / \mathrm{kg}$ & $\mathrm{HJ} 455-2009$ & $\leq 10$ & not detected & Compliance with standard \\
\hline 2 & soluble $\mathrm{Cd}, \mathrm{mg} / \mathrm{kg}$ & $\mathrm{HJ} 455-2009$ & $\leq 10$ & not detected & Compliance with standard \\
\hline 3 & soluble $\mathrm{Cr}, \mathrm{mg} / \mathrm{kg}$ & $\mathrm{HJ} 455-2009$ & $\leq 10$ & $\mathbf{0 . 3}$ & Compliance with standard \\
\hline 4 & soluble $\mathrm{Hg}, \mathrm{mg} / \mathrm{kg}$ & $\mathrm{HJ} 455-2009$ & $\leq 10$ & not detected & Compliance with standard \\
\hline
\end{tabular}

Notes: the data is from Certification and inspection report of environmental mark products (Inspection Report No.: HJ2019ZL0633)

Table 2. Test results of SBS II PY PE PE 4 elastomer modified asphalt waterproofing membrane

\begin{tabular}{|l|l|l|c|l|l|}
\hline No. & \multicolumn{1}{|c|}{ Test content } & Test Standard & $\begin{array}{c}\text { Standard } \\
\text { requirements }\end{array}$ & \multicolumn{1}{|c|}{ Test results } & \multicolumn{1}{|c|}{ Judgment result } \\
\hline 1 & soluble $\mathrm{Pb}, \mathrm{mg} / \mathrm{kg}$ & $\mathrm{HJ} 455-2009$ & $\leq 10$ & not detected & Compliance with standard \\
\hline 2 & soluble $\mathrm{Cd}, \mathrm{mg} / \mathrm{kg}$ & $\mathrm{HJ} 455-2009$ & $\leq 10$ & not detected & Compliance with standard \\
\hline 3 & soluble $\mathrm{Cr}, \mathrm{mg} / \mathrm{kg}$ & $\mathrm{HJ} 455-2009$ & $\leq 10$ & $\mathbf{0 . 6}$ & Compliance with standard \\
\hline 4 & soluble $\mathrm{Hg}, \mathrm{mg} / \mathrm{kg}$ & $\mathrm{HJ} 455-2009$ & $\leq 10$ & not detected & Compliance with standard \\
\hline
\end{tabular}

Notes: the data is from Certification and inspection report of environmental mark products (Inspection Report No.: HJ2019ZL0631)

\subsection{Physical property}

Compared with the traditional modified asphalt waterproofing membrane, the high polymer (HDPE) self-adhered waterproofing membrane has outstanding advantages in physical properties. Taking SBS II PY PE PE 4 modified asphalt waterproofing membrane as an example, the main performance indexes of high polymer (HDPE) self-adhered waterproofing membrane are better than that of traditional waterproofing membrane, such as tensile property, tear strength, low-temperature bending property and water resistance.

\section{Construction superiority of high polymer (HDPE) self-adhered waterproofing membrane}

\subsection{Saving materials}

The high polymer (HDPE) self-adhered waterproofing membrane, which is bonded by the adhesive membrane on the surface of the membrane and the concrete structural plate, is constructed by the pre-laying and antisticking method, and a single layer can reach the first level of fortification, which is equivalent to two layers of traditional SBS modified asphalt waterproofing membrane, and the same waterproof fortification level saves a layer of waterproof material. The width of traditional SBS waterproofing membrane is $1000 \mathrm{~mm}$ and the lap width is $100 \mathrm{~mm}$, while the width of HDPE selfadhered waterproofing membrane is $2000 \mathrm{~mm}$ and the lap width is $80 \mathrm{~mm}$, reducing the lap loss between the same layer and different layers. At the same time, the lap loss is low, and the lap gap is small. According to the statistical comparison of entity data required by the same waterproof level of many different projects, the laying area of high polymer (HDPE) self-adhered waterproofing membrane building materials is saved by about $1 / 2$, the construction comprehensive cost is saved by $1 / 3$, and the construction period is saved by $1 / 3$ through comprehensive analysis. It is of great significance to save materials and reduce losses.

\subsection{Convenient process and low energy consumption}

The construction process of high polymer (HDPE) selfadhered waterproofing membrane includes base treatment, detail node strengthening, positioning laying, lapping and coiling. Compared with the traditional SBS waterproofing membrane construction process, the interlayer lapping process and hot melt lapping process are saved. High polymer (HDPE) self-adhered waterproofing membrane is convenient and efficient in construction, which can effectively shorten the construction period and reduce labor consumption under the same requirements of waterproof quality.

\subsection{Construction safety and environmental protection}

The construction of high polymer (HDPE) self-adhered waterproofing membrane adopts the method of prelaying and anti-sticking construction supporting construction auxiliary materials to carry out waterproof laying construction. During the construction process, no open fire operation is required, no asphalt smoke is generated, so as to reduce the fire hazard and safety risk. However, the traditional SBS waterproofing membrane construction needs open fire operation. The base course, additional layer and interlayer overlap are treated by hot melting, which produces toxic and harmful gases such as asphalt smoke and pollutes the atmosphere. At the same time, the asphalt tar produced in the construction process has a strong permeability, which also has potential pollution to the soil. In contrast, high polymer (HDPE) self-adhered waterproofing membrane is more safely and environmentally friendly in the construction process. 


\subsection{Little environmental impact on Construction}

Compared with the traditional SBS waterproofing membrane, the high polymer (HDPE) self-adhered waterproofing membrane has a lower requirement on the moisture content of the construction base. Without open water in the base, the construction conditions can be met, the construction interval can be effectively shortened, the reasonable process lap can be achieved, and the loss of labor force can be reduced. For the construction of high polymer (HDPE) self-adhered waterproofing membrane, the construction environment temperature is $5-35{ }^{\circ} \mathrm{C}$, if winter construction is involved, it is easy to choose the welding form to overlap, the construction environment temperature can reach $-10{ }^{\circ} \mathrm{C}$, the construction is flexible, and the environment adaptability is strong.

\subsection{Construction quality assurance}

Take the bottom slab of underground structure as an example, the traditional SBS waterproofing membrane is constructed on the cushion layer, and the waterproofing membrane is bonded downward. Due to the large number of layers and joints, the hidden danger of joints is prone to water channeling, which is easy to cause the surface water to erode the concrete structure through the joints, leading to leakage or seepage. The waterproofing principle of high polymer (HDPE) self-adhered waterproofing membrane is pre-laying and anti-sticking construction. The coiled material is wrapped up with the concrete main structure bottom plate to realize the substantial water facing surface waterproofing. By fully bonding with the main structure, the phenomenon of water channeling is reduced and the quality of waterproofing works is guaranteed. In the construction process, compared with the traditional SBS modified asphalt waterproofing membrane, its waterproof performance is more excellent.

\subsection{Construction cost comparison}

With the same waterproof level, one layer of high polymer (HDPE) self-adhered waterproofing membrane is equivalent to two layers of traditional SBS modified asphalt waterproofing membrane, saving materials. At the same time, after the completion of waterproof construction, the high polymer (HDPE) self-adhered waterproofing membrane does not need to be applied with waterproof protective layer, and can directly carry out the process of steel bar binding and main building concrete pouring. The traditional SBS modified asphalt waterproofing membrane needs to be provided with a waterproof protective layer before the construction of the main structure of the building. In the true sense, high polymer (HDPE) self-adhered waterproofing membrane has achieved process saving, material saving, labor saving and cost saving.

\section{Conclusion}

Through the comparative analysis of high polymer (HDPE) self-adhered waterproofing membrane and traditional waterproofing membrane, it can be seen that high polymer (HDPE) self-adhered waterproofing membrane has outstanding green environmental protection features, such as low energy consumption, high efficiency, pollution-free, multi-function, etc. from its own development and waterproof mechanism to construction process. In today's high-speed development society, with the continuous improvement of people's requirements for quality of life and awareness of environmental protection, the concept of green environmental protection has gradually become a new direction of the construction industry. Under the condition of meeting the basic functions of building materials, the construction industry gradually pays attention to the concept of green environmental protection and sustainable development, and prefers to choose green environmental protection building materials. The development and selection of green building materials will help the construction industry to achieve sustainable development. The reasonable use of green environmental protection materials in the construction industry can effectively protect and improve the ecological environment. In this paper, through the comparison of material characteristics and construction technology, the advantages of high polymer (HDPE) self-adhered waterproofing membrane as green building materials are compared with traditional waterproofing membrane.

\section{Acknowledgements}

Thanks for the technical support of Tangshan Yuandahongyu Waterproof Material Co., Ltd.

\section{References}

1. K. Yang. Building materials industry information, 67(2004).

2. D. Yang, C Wang, H Yang..China Building Waterproofing. 31-33(2019).

3. K. Zhao, Y. Ma, X. Wang. Intelligent city. 7(2020).

4. Z. Li, China housing facilities, 2020.115-116

5. T. Ouyang, Journal of Jiamusi Vocational College.7 (2020).

6. Technical requirement for environmental labeling products -waterproof rolling materials ( HJ 4552009) 